\title{
Entre pruebas y caretas: percepción sobre el reinicio de la endoscopia digestiva durante la COVID-19
}

\author{
Jorge Sandoval-Montero ${ }^{*}$, Wagner Ramírez-Quesada², Silvia Molina-Castro ${ }^{3}$, Vanessa Ramírez-Mayorga ${ }^{4}$, \\ Vivian Araya-Arce ${ }^{5}$, Irene Vargas-Soto ${ }^{6}$ y José Moreno-Araya ${ }^{7}$ \\ ${ }^{1}$ Departamento de Gastroenterología, Hospital de Guápiles, Limón; ${ }^{2}$ Departamento de Gastroenterología, Centro de Atención Integral en Salud de \\ Puriscal, San José, Puriscal; ${ }^{3}$ Escuela de Medicina, Departamento de Bioquímica, Instituto de Investigaciones en Salud, Universidad de Costa \\ Rica, San José; ${ }^{4}$ Escuela de Nutrición, Instituto de Investigaciones en Salud, Universidad de Costa Rica, San José; ${ }^{5}$ Departamento de \\ Gastroenterología, Hospital Max Peralta, Cartago; ${ }^{6}$ Departamento de Gastroenterología, Clínica Marcial Fallas, San José; ${ }^{7}$ Departamento de \\ Gastroenterología, Hospital de San Rafael de Alajuela, Alajuela. Costa Rica
}

\section{Resumen}

Introducción: COVID-19 ha generado una pausa en la endoscopia electiva, retrasando el diagnóstico de múltiples patologías. Existen varias propuestas para reiniciar las actividades que incluyen el tamizaje por COVID-19 y un reinicio escalonado. Objetivo: Conocer la percepción general de los endoscopistas respecto al reinicio de procedimientos electivos, y la influencia que genera la disponibilidad de equipo de protección personal (EPP) y tamizaje. Metodología: Se encuestan endoscopistas expertos con preguntas enfocadas a la endoscopia durante la pandemia, así como de disponibilidad de EPP y del uso de pruebas de tamizaje de SARS-CoV-2. La encuesta fue distribuida vía e-mail, mensajería instantánea y por contacto directo a distintas sociedades de endoscopia, obteniendo respuesta completa de 168 médicos. Resultados: 88\% de los encuestados no practican tamizaje por COVID-19 sin embargo un $70 \%$ considera apropiada esta práctica. El 80\% afirma contar con EPP adecuado. El 94\% de los médicos afirma que deben reiniciarse los procedimientos lo antes posible. Conclusiones: Los endoscopistas latinoamericanos con mayor disponibilidad de EPP, así como la implementación de tamizaje de SARS-CoV-2, presentaron mayor disposición a reiniciar las endoscopias electivas.

Palabras clave: COVID-19. Endoscopia. Pruebas de tamizaje. Equipo de protección personal (EPP).

\section{Amongst tests and masks: Perception about the restart of digestive endoscopy during COVID-19}

\begin{abstract}
Introduction: COVID-19 has paused elective procedures and delayed the diagnosis of multiple pathologies. Different proposals have been recommended for restarting elective procedures, including screening tests and a gradual restart. Objective: To know the perception of Latin American endoscopists regarding the restart of elective procedures, and how the availability of personal protection equipment (PPE) and prior testing may influence this perception. Methods: A web-based survey was developed by endoscopy experts, based in the development of endoscopy, availability of PPE and screening tests, which was distributed via e-mail, social media and direct contact by one author to several societies. Full response was obtained from 168 endoscopists during May 2020. Results: 88\% of surveyed endoscopists don't screen for COVID-19 prior to endoscopy, however, 70\% consider this appropriate. $80 \%$ affirm having PPE. 94\% believe that endoscopic practice must be restarted as soon as possible. Conclusions: Latin American endoscopists with greater amount of PPE and prior testing for SARS-CoV-2 were more willing to restart elective procedures than those in limited scenarios.
\end{abstract}

Key words: COVID-19. Endoscopy. Screening tests. Personal protection equipment (PPE).

\footnotetext{
Correspondencia:

*Jorge Sandoval-Montero

E-mail: joralonsan@gmail.com

Disponible en internet: 06-11-2020

Endoscopia. 2020;32(4):111-119

www.endoscopia-ameg.com 


\section{Introducción}

En enero de 2020, la Organización Mundial de la Salud (OMS) declaró la enfermedad por coronavirus 2019 (COVID-19) como emergencia de salud pública y el 11 de marzo como un estado de pandemia1.

En junio del 2020 se sobrepasaron los 6,000,000 de casos, con al menos 375,000 fallecidos, lo que refleja la gravedad del impacto mundial ${ }^{2}$.

El conocimiento sobre el coronavirus 2 del síndrome respiratorio agudo grave (SARS-CoV-2), el cual provoca la enfermedad, es limitado debido a su reciente aparición, sin embargo se ha establecido que es altamente transmisible, cada portador puede infectar al menos tres personas más, por lo que se recomienda el distanciamiento social como forma de prevención $n^{1,3}$.

EI SARS-CoV-2 se puede adquirir por contacto directo 0 de forma indirecta por contacto con superficies y objetos $^{1,4}$.

La pandemia ha traído retos que los sistemas de salud han tenido que enfrentar, entre ellos destacan el riesgo de infección en trabajadores de la salud, escasez de equipos de protección personal (EPP) y saturación de camas en las unidades de cuidados intensivos, entre otros, que han expuesto carencias a nivel mundial ${ }^{4,5}$.

La mayoría de los países implementaron medidas de confinamiento para enlentecer el pico de incidencia de COVID-19, evitando así la sobrecarga de los servicios de salud; en el caso de la endoscopia, la mayoría de las sociedades suspendieron procedimientos electivos para evitar la propagación del virus, atendiendo exclusivamente emergencias y casos oncológicos ${ }^{5-7}$.

En EE.UU. la suspensión de endoscopia retrasaría el diagnóstico de más de 2,800 casos de cáncer colorrectal y 22,000 pólipos con displasia de alto grado, aumentando la tasa de mortalidad a seis meses en un $6.5 \%$. Considerando que hay más de 600,000 portadores de cirrosis, se estima que más de 1,500 presentarán un sangrado variceal ${ }^{8}$.

Ante la falta de evidencia, la mayoría de las sociedades basan recomendaciones en opiniones de experto, donde incluyen la implementación de tamizaje por COVID-19 previo al estudio y con base en los resultados modificar el uso de EPP, o diferir en casos positivos $^{6-8}$.

Repici, et al. evaluaron la incidencia de COVID-19 en pacientes y personal de salud con uso adecuado de EPP, concluyendo que el riesgo de infección es bajo ${ }^{9}$.

El presente estudio tiene como objetivo conocer la perspectiva de los endoscopistas respecto al reinicio de endoscopia electiva en tiempos de COVID-19.

\section{Pruebas de detección de SARS-CoV-2}

Léase: La confirmación diagnóstica de SARS-CoV-2 es mediante detección de ARN viral por reacción en cadena de la polimerasa en tiempo real (RT-PCR $)^{10-13}$. Otros métodos de detección se basan en la tecnología CRISPR(Clustered Regularly Interspaced Short Palindromic Repeats)-Cas ${ }^{14}$ o en amplificación isotérmica, pero su uso no es tan extendido ${ }^{15}$.

La muestra de elección es el hisopado nasofaríngeo, aunque los protocolos pueden adaptarse a otras muestras como lavados broncoalveolares ${ }^{16}$. Algunos estudios han utilizado saliva como muestra, ya que es de fácil obtención y permite detectar ARN viral por más tiem$\mathrm{po}^{17,18}$. Sin embargo, otros estudios sugieren lo contrario al evaluar una población extrahospitalaria ${ }^{15}$. Además, los métodos de obtención de la saliva no son homogéneos, lo cual podría explicar las diferencias encontradas. La utilización de esta muestra deberá estandarizarse antes de aplicarse de forma sistemática ${ }^{19}$.

La alternativa diagnóstica es la detección sérica de anticuerpos $\lg M$ e $\lg G$. Se han desarrollado inmunoensayos enzimáticos, que permiten la detección y cuantificación relativa ${ }^{20-22}$. También se han desarrollado pruebas rápidas, basadas en técnicas de inmunoprecipitación de flujo lateral que brindan resultados cualitativos de presencia o ausencia de anticuerpos, que incluso pueden utilizar sangre total sin la fase previa de separación del suero ${ }^{23}$.

Existen gran cantidad de pruebas rápidas, con diferente sensibilidad y especificidad, sin embargo requieren validarse en cada población frente a las técnicas de detección de ARN viral y anticuerpos por ensayos cuantitativos antes de ser utilizadas. Algunos estudios revelan gran heterogeneidad entre ellas, además reportan variaciones dependientes de la interpretación del lector y de la etapa de la infección en la cual se aplican, lo que limita su uso 24,25 .

\section{Aplicación de pruebas como criterio para reinicio de las endoscopias electivas}

Con los métodos disponibles, la detección del ARN viral puede iniciar desde el día siguiente al inicio de los síntomas, siendo significativa la probabilidad a partir del día 3 y alcanzando su pico al cumplirse una semana. A partir de ese momento, la detección de ARN viral va disminuyendo, a menos que el paciente empeore su condición, ya que en una presentación clínica severa puede mantenerse por varias semanas ${ }^{26}$. 


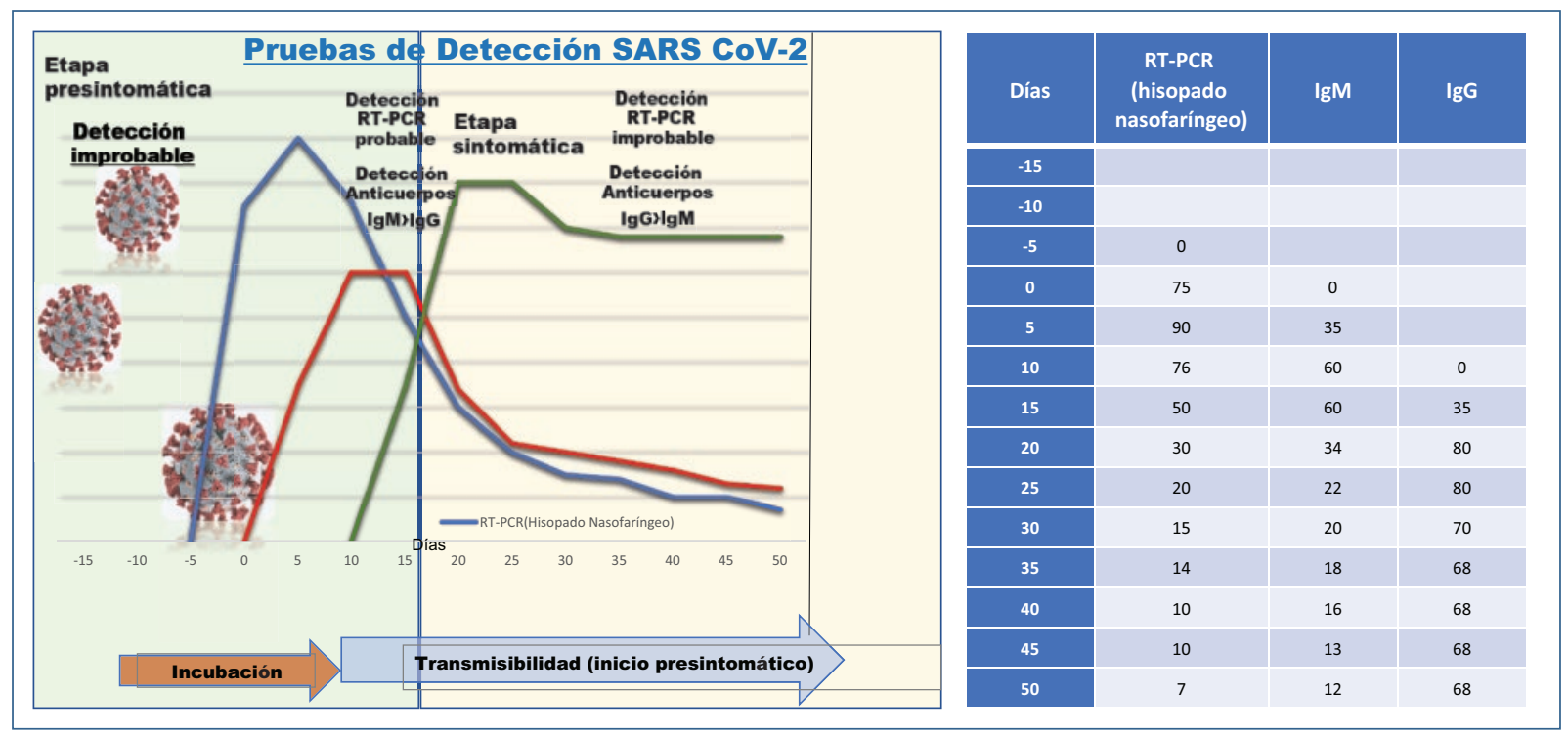

Figura 1. Variación estimada en el tiempo en las pruebas de diagnóstico para la detección de COVID-19 respecto al inicio de los síntomas. Los intervalos de tiempo estimados se basan en datos publicados en diferentes reportes, por lo cual son aproximaciones (adaptada de Ben-Assa, et al., $2020^{16}$ y Wölfel, et al., 202027).

RT-PCR: reacción en cadena de la polimerasa en tiempo real; IgM: inmunoglobulina M; IgG: inmunoglobulina G.

Por otro lado, los anticuerpos son detectables al iniciar la segunda semana desde el inicio de los síntomas $^{27,28}$. En promedio, el rango de positivización de la IgM está entre los días 5 y 10 a partir de la presentación clínica, mientras que para la lgG el rango varía entre los días 13 y $21^{22}$. Guo, et al. demostraron positivización de IgM con un intervalo del día 3 al 6 , mientras que la IgG presentó positivización entre los días 10 y $18^{21,22}$. Este trabajo se realizó en pacientes con síntomas severos, lo cual podría explicar la aparición más temprana.

La selección de la prueba depende del momento de la infección, la presentación clínica y el propósito de esta; de tal manera que la detección de ARN viral es útil como confirmación diagnóstica de infección aguda y como criterio para dar de alta a un paciente sintomático, mientras que la detección de anticuerpos es útil para comprobar infección reciente o pasada, entre otros, sin embargo ninguna prueba puede garantizar ausencia de infección en estadios muy tempranos, en los que la persona infectada ya cuenta con potencial para transmitir el virus (Fig. 1) 14,15,25.

\section{Metodología}

Se realizó una encuesta (Tabla 1) en forma consensuada por parte de expertos en endoscopia con preguntas enfocadas al desarrollo de la endoscopia durante la pandemia, así como de disponibilidad de EPP y del uso de pruebas de tamizaje de SARS-CoV-2 previo a la endoscopia durante el mes de mayo 2020, la cual fue distribuida vía e-mail, mensajería instantánea y por contacto directo, obteniendo respuesta de 168 endoscopistas latinoamericanos, que la completaron en forma voluntaria y completa. Se formularon ocho preguntas, que se distribuyeron de la siguiente forma: tres sobre información del endoscopista y situación actual con respecto a la pandemia, dos acerca del uso de pruebas de tamizaje, dos sobre la disponibilidad de EPP y una acerca del reinicio de la actividad endoscópica. Con base en las preguntas se tabularon datos mediante Excel, obteniendo frecuencias simples, las cuales fueron analizadas mediante cruce de variables.

Los resultados de la encuesta fueron manejados únicamente por los investigadores, esto con el fin de mantener la información recogida con total confidencialidad y anonimato.

\section{Resultados}

La encuesta se llevó a cabo durante el mes de mayo 2020 por un periodo de dos semanas, donde se registraron 168 participantes de 18 países, la mayoría latinoamericanos. Una tercera parte de los encuestados 
Tabla 1. Cuestionario respecto a reinicio de endoscopia en tiempos de COVID-19

Cuestionario respecto a reinicio de endoscopia en tiempos de COVID-19

1. ¿Su práctica endoscópica la realiza en el sector: privado y/o público?

2. ¿En qué país de Latinoamérica desarrolla su actividad médica?

3. ¿En su país realizan pruebas de detección o tamizaje en pacientes asintomáticos (PCR o anticuerpos) previo a la endoscopia digestiva?

4. ¿Considera adecuado realizar test diagnósticos de COVID -19 (PCR o anticuerpos) en pacientes asintomáticos antes de la endoscopia digestiva?

5. ¿La unidad de endoscopia donde usted trabaja, cuenta con el equipo completo de protección (EPP) para atender un paciente con diagnóstico positivo de COVID-19?

6. Con respecto a la pregunta anterior, el suministro de equipo de protección (EPP) de su unidad de endoscopia tiene una reserva: ¿para menos de 7 días, de 7 a 28 días, 0 más de 28 días?

7. En relación con la COVID-19 en su comunidad (área de atracción), ¿en cuál etapa se encuentran?

8. ¿Considera adecuado reiniciar gradualmente las actividades endoscópicas electivas en la unidad de endoscopia donde usted trabaja?

COVID-19: enfermedad por coronavirus 2019; PCR: reacción en cadena de la polimerasa; EPP: equipo de protección personal.

provenían de Costa Rica y en segundo lugar de Bolivia, con $14 \%$ de participantes (Fig. 2).

El $48 \%(n=80)$ realizan la práctica de endoscopia digestiva tanto en el ámbito público como en el privado, mientras el $40 \%$ ( $n=67)$ únicamente ejerce a nivel privado. De acuerdo con el comportamiento epidemiológico, el 35\% ( $n=59)$ están en áreas de atracción, con rápido aumento de casos nuevos de COVID-19, representados mayoritariamente por Bolivia (23\%, $\mathrm{n}=14)$ y República Dominicana $(20 \%, \mathrm{n}=12)$. Solamente el $4 \%(n=8)$ realizan estudios endoscópicos en zonas sin casos nuevos por al menos dos semanas consecutivas, representado en un $50 \%$ de los casos por Venezuela (Tabla 2).

El $88 \%(n=148)$ de los encuestados no realizan tamizaje a pacientes asintomáticos previo a una endoscopia, sin embargo el $70 \%(n=127)$ lo consideran útil; la distribución de profesionales que llevan a cabo esta prueba se observa en la tabla 3. En cuanto al EPP completo, el $80 \%(n=131)$ afirmaron contar con este, pero un $35 \%(n=59)$ tienen una reserva para menos de siete días de actividad; pese a esto, un $77 \%(n=130)$ consideran apropiado reiniciar los estudios electivos (Fig. 3).

La disponibilidad de EPP es mayor $(46 \%, n=61)$ en aquellos que ejercen tanto a nivel privado como público, mientras el $11 \%(n=15)$ de aquellos dedicados al
Tabla 2. Distribución simple de resultados de encuesta practicada a los endoscopistas

\begin{tabular}{|c|c|}
\hline Variable encuestada & $n=168(\%)$ \\
\hline \multicolumn{2}{|l|}{ Tipo de práctica } \\
\hline Privado & $67(40)$ \\
\hline Publico & 21 (12.5) \\
\hline Público y privado & $80(47.5)$ \\
\hline \multicolumn{2}{|l|}{ Tamizaje a pacientes asintomáticos } \\
\hline No & $148(88)$ \\
\hline Sí & $20(11)$ \\
\hline \multicolumn{2}{|l|}{$\begin{array}{l}\text { Posición acerca de realización de estudio en } \\
\text { pacientes asintomáticos }\end{array}$} \\
\hline No & $43(25.5)$ \\
\hline Sí & $125(74.5)$ \\
\hline \multicolumn{2}{|l|}{ Presencia de EPP en UE } \\
\hline No & $37(22)$ \\
\hline Sí & $131(78)$ \\
\hline \multicolumn{2}{|l|}{ Tiempo de reservas de EPP } \\
\hline 12 semanas o más & $12(7)$ \\
\hline De 4 a 8 semanas & $38(22.6)$ \\
\hline Menor a 4 semanas & $59(35.2)$ \\
\hline Menor a 7 días & $59(35.2)$ \\
\hline \multicolumn{2}{|l|}{ Etapa epidemiológica } \\
\hline Aumento exponencial en nuevos casos & $45(27)$ \\
\hline No hay nuevos casos (por al menos 2 semanas) & $8(5)$ \\
\hline Rápido aumento de casos nuevos & $59(35.2)$ \\
\hline Tendencia a la baja en nuevos casos & $56(32.8)$ \\
\hline \multicolumn{2}{|l|}{$\begin{array}{l}\text { Posición acerca de reinicio de actividades } \\
\text { electivas en UE }\end{array}$} \\
\hline No & $38(23)$ \\
\hline Sí & 130 (77) \\
\hline
\end{tabular}

UE: Unidad de Endoscopia; EPP: equipo de protección.

sector público cuentan también con el mismo recurso. Si se realiza el análisis por país, aproximadamente el $77 \%(n=130)$ de las unidades de endoscopia del territorio latinoamericano cuentan con EPP completo (Fig. 4).

El $94 \%(n=53)$ de endoscopistas costarricenses estuvieron de acuerdo con reiniciar la endoscopia electiva, representando el $40 \%$ de latinoamericanos con esta posición, mientras que una postura negativa es más frecuente en médicos bolivianos (Fig. 4).

\section{Discusión}

El presente estudio tiene como objetivo conocer la percepción subjetiva de endoscopistas en distintos países de Latinoamérica respecto al reinicio de endoscopia electiva en tiempos de COVID-19, y la influencia que genera la disponibilidad de EPP y pruebas de tamizaje en ella. 


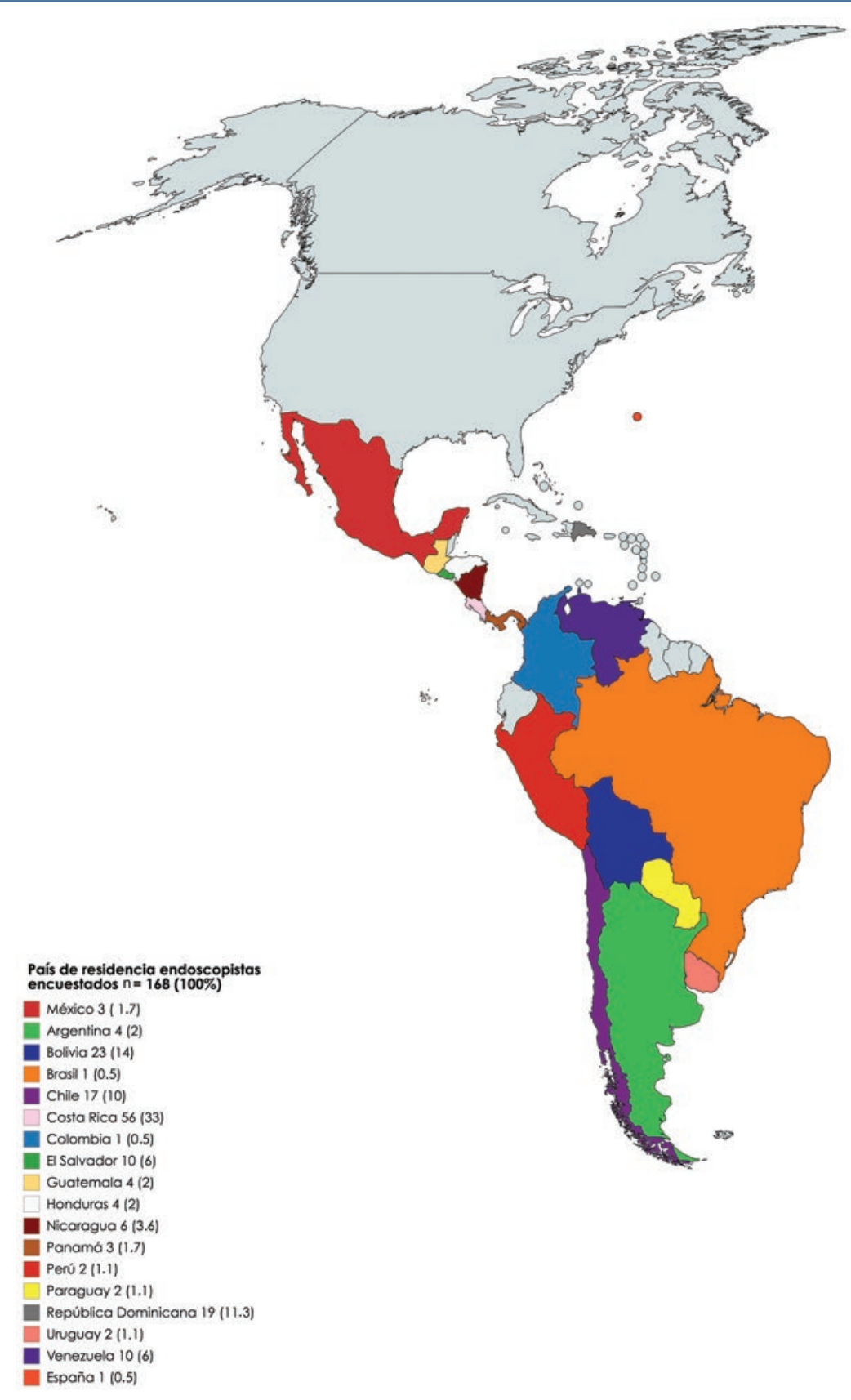

Figura 2. Distribución en mapa de país de residencia de la mayoría de los endoscopistas encuestados.

Desde el inicio de la pandemia distintas medidas de aislamiento surgen en respuesta a lo observado en países donde, una vez iniciado el contagio, el contacto de personas de forma habitual llevó a una rápida transmisión comunitaria del virus, con la posterior saturación del sistema hospitalario ${ }^{1,2}$. Es inevitable una disminución drástica en la realización de procedimientos, lo cual tiene un impacto en detección y tratamiento de diversas patologías del tracto gastrointestinal. Conforme avanzan las semanas, es imperativo desarrollar lineamientos para reiniciar procedimientos electivos ${ }^{6,7}$.

Forbes, et al. analizan medidas instauradas por centros de salud mediante una encuesta que permite 
Tabla 3. Endoscopistas encuestados que realizan pruebas de detección previo a endoscopia según país de origen

\begin{tabular}{|c|c|}
\hline $\begin{array}{l}\text { Endoscopistas encuestados que realizan pruebas de } \\
\text { detección previo a endoscopia según país de origen }\end{array}$ & $\mathrm{n}=20(\%)$ \\
\hline Bolivia & $2(10)$ \\
\hline Chile & $2(10)$ \\
\hline Costa Rica & $4(20)$ \\
\hline España & $1(5)$ \\
\hline Honduras & $1(5)$ \\
\hline Panamá & $1(5)$ \\
\hline Perú & $1(5)$ \\
\hline República Dominicana & $5(25)$ \\
\hline Uruguay & $1(5)$ \\
\hline Venezuela & $2(10)$ \\
\hline Total & $20(100)$ \\
\hline
\end{tabular}

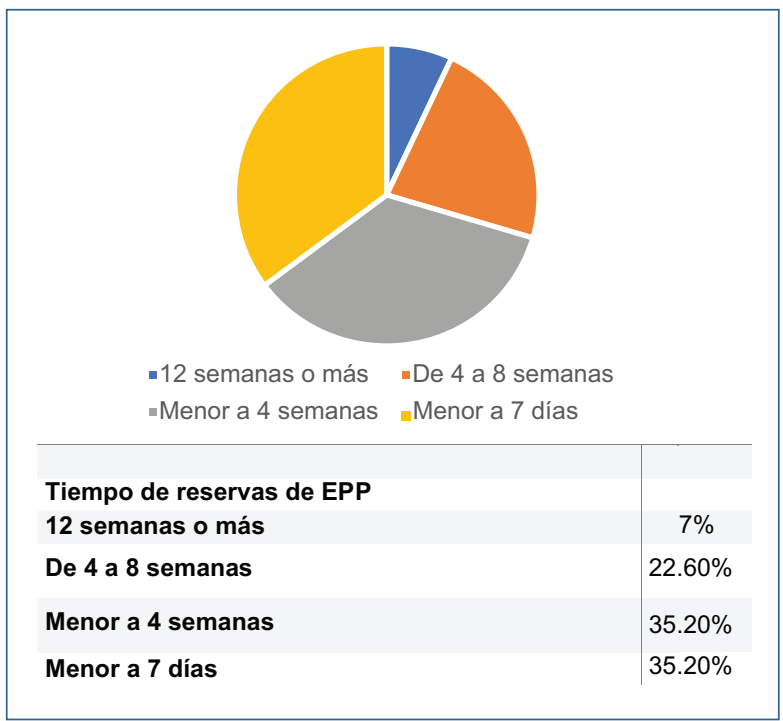

Figura 3. Tiempo de disponibilidad de equipo de protección personal según endoscopistas encuestados.

analizar el impacto generado por estas en la atención de pacientes, en el entrenamiento en endoscopia y el uso de EPP ${ }^{8}$. Además, sugieren que el rendimiento de pruebas de tamizaje es bajo y al no modificar la recomendación de uso completo de EPP podría omitirse en escenarios de recursos limitados?

La encuesta realizada tomó la opinión de 168 endoscopistas de 18 países distintos, donde el $77 \%$ consideraron apropiado reiniciar las actividades endoscópicas electivas. Un aspecto clave para apoyar el reinicio es la disponibilidad de EPP, donde un $80 \%$ de los entrevistados afirman contar con él; sin embargo, el $35 \%$ consideran tener reservas necesarias solamente para siete días (Fig. 3).

Durante situaciones de escasez de respiradores, la sociedad americana de enfermedades infecciosas favorece reutilizarlos mediante técnicas de desinfección como el uso de peróxido de hidrógeno vaporizado, irradiación germicida ultravioleta o calor seco a 70-80 grados. La reutilización debería considerarse incluso en ausencia de escasez, en forma preventiva. Otra recomendación es agregar un protector facial o una mascarilla quirúrgica como cubierta para el respirador, de modo que se logre prolongar su uso 29,30.

Otra variable importante es la fase de transmisión en que se encuentra cada país, donde el $61 \%$ de los encuestados laboran en áreas con rápido aumento de casos nuevos, por lo que el reinicio de las actividades debe realizarse bajo estrictos protocolos de funcionamiento, con el fin de minimizar la posibilidad de infección. Es importante considerar que los resultados obtenidos no se pueden extrapolar a Latinoamérica, ya que se trató de una muestra a conveniencia, con una subrepresentación de países con alta densidad demográfica como México y Brasil.

La Sociedad de Endoscopia Digestiva de Asia-Pacífico emitió recomendaciones acerca del reinicio de endoscopia electiva, considerando número y curva epidémica de casos de COVID-19, disponibilidad de EPP y volumen acumulado de casos electivos pospuestos ${ }^{31}$. Según lo recomendado, mientras un país se encuentre en fase de crecimiento exponencial de casos o cuente con reservas de EPP menores a 1 mes debería abstenerse de realizar procedimientos electivos, mientras que si se encuentra en una etapa con tendencia a la baja o cuenta con reservas para 4-8 semanas, podría reiniciarse con el $50 \%$ de la actividad. Cuando no se detecten casos nuevos por al menos dos semanas y se cuente con al menos 12 semanas de reserva de EPP, se debería reiniciar con el 100\% de la capacidad 31,32 .

Se ha planteado el tamizaje por COVID-19 72 horas previo al estudio electivo, sin embargo se debe considerar la posibilidad de infección entre el momento de realización de la prueba y el procedimiento endoscópico ${ }^{6}$.

El $77 \%$ de los encuestados consideran importante realizar pruebas de detección previo a la endoscopia, sin embargo lo anterior debe considerarse con cautela, 


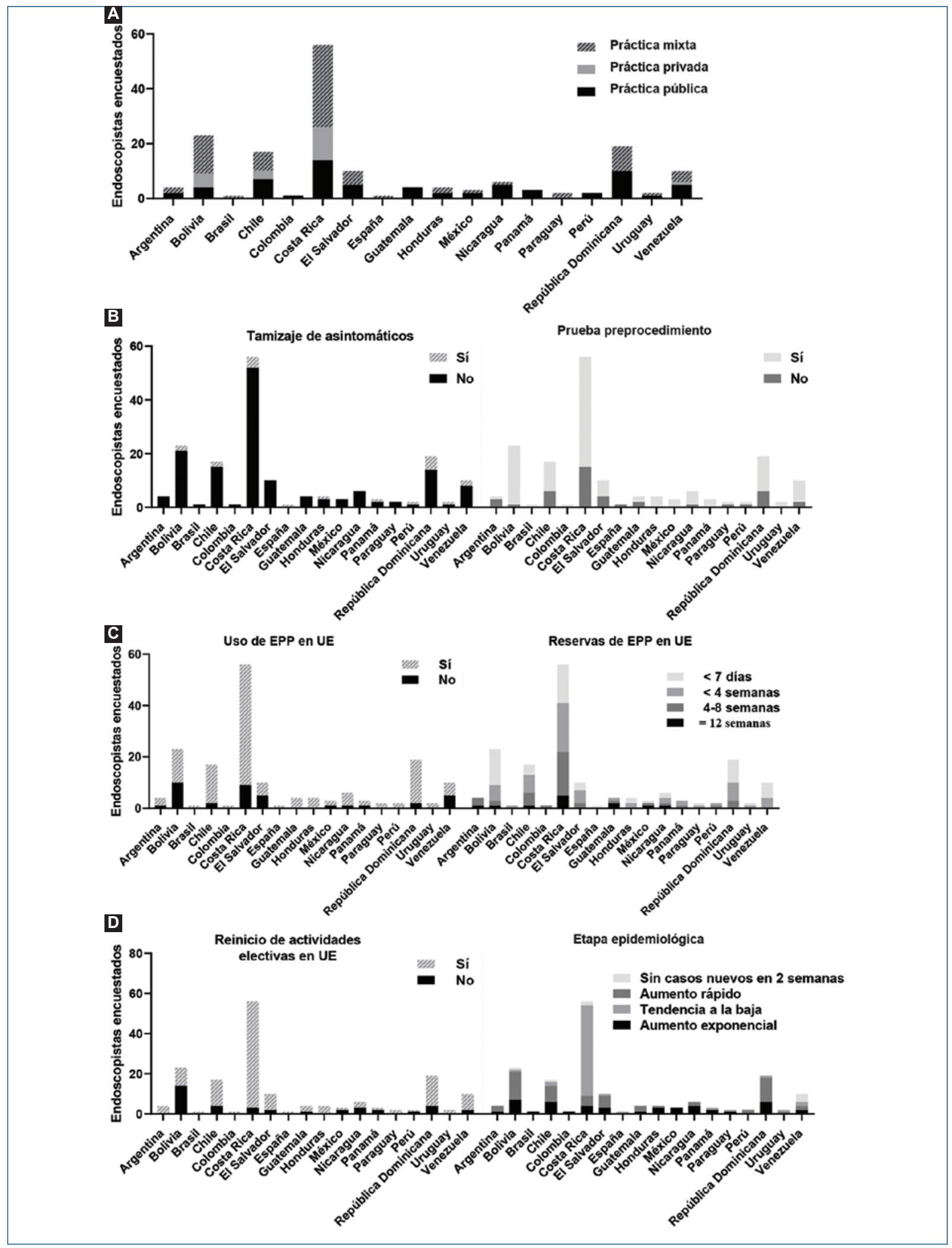

Figura 4. Resultados mediante gráfico de barras de la encuesta electrónica por país de residencia realizada a los 168 endoscopistas. A: endoscopistas según distribución en medicina pública, privada o mixta. B: tamizaje de pacientes asintomáticos previo al procedimiento. C: uso y reservas de EPP. D: reinicio de actividades electivas en la UE y etapa epidemiológica del país, respectivamente.

UE: Unidad de Endoscopia; EPP: equipo de protección. 
ya que todas las pruebas presentan limitaciones en detección de pacientes potencialmente infecciosos en etapas tempranas de la enfermedad ${ }^{27}$.

El panorama se complica con portadores asintomáticos, especialmente en el ámbito comunitario, ya que el periodo de detección se desconoce, debido a que no existe un punto de partida correspondiente al inicio de los síntomas. Otro desafío son los casos muy leves con carga viral muy baja ${ }^{33}$. Este hecho cobra mayor relevancia al tomar en cuenta que las personas pueden excretar partículas virales viables e infecciosas desde 1-4 días antes del inicio del cuadro clínico 27-34; por otro lado, los anticuerpos tienen un periodo de positivización mayor, por lo que su utilidad para descartar infección aguda es menor ${ }^{34,35}$. Por ende, una prueba negativa no garantiza que el paciente no es infeccioso y no exime al personal de salud de utilizar EPP completo.

\section{Conclusión}

El presente estudio presenta limitaciones importantes al ser de tipo descriptivo, observacional y carente de un análisis estadístico específico basado en su encuesta, además es dependiente del momento epidemiológico de cada uno de los encuestados. Por otro lado, la mayor fortaleza del estudio corresponde a brindar una valoración subjetiva de los endoscopistas latinoamericanos donde se logra determinar que los encuestados con mayor disponibilidad de EPP, así como pruebas de tamizaje, presentan mayor disposición para reiniciar procedimientos electivos, como sucede con un $77 \%$ de los encuestados. Además se realiza una revisión de la utilidad real de las pruebas en forma de tamizaje demostrando importantes carencias que pueden tener impacto y limitar su uso de forma sistemática.

Es importante destacar que debido a la rápida evolución de la pandemia COVID-19 es probable que las recomendaciones pronto requieran actualizarse.

\section{Financiamiento}

La presente investigación no ha recibido ayudas específicas provenientes de agencias del sector público, sector comercial o entidades sin ánimo de lucro.

\section{Conflicto de intereses}

Los autores declaran no tener conflicto de intereses.

\section{Responsabilidades éticas}

Protección de personas y animales. No se han realizado experimentos en humanos ni animales.

Confidencialidad de datos. Los autores han seguido los protocolos de su centro de trabajo sobre la publicación de datos de pacientes.

Derecho a la privacidad y consentimiento informado. Los autores declaran que en este artículo no aparecen datos de pacientes.

\section{Bibliografía}

1. Ruiz-Manríquez J, León-Lara X, Campos-Murguía A, Solis-Ortega AA, Pérez-González B, Uscanga LF, et al. Conocimiento sobre la infección por SARS-CoV-2 de gastroenterólogos y endoscopistas de Latino América. Rev Gastroenterol Mex. 2020;85(3):288-94.

2. COVID-19 Dashboard by the Center for Systems Science and Engineering at Johns Hopkins, Johns Hopkins University Center, Coronavirus Resource Center, 2020 [Internet]. Johns Hopkins University \& Medicine, Coronavirus Resource Center [fecha de acceso: 01/06/2020]. Disponible en: https://coronavirus.jhu.edu/map.html

3. Prevención y control de las infecciones respiratorias agudas con tendencia epidémica y pandémica durante la atención sanitaria [Internet]. Organización Mundial de la Salud; 2014 [fecha de acceso: 26/05/2020]. Disponible en: https://www.paho.org/hq/dmdocuments/2014/2014-cha-prevencion-control-atencion-sanitaria.pdf

4. Liu J, Liao X, Qian S, Yuan J, Wang F, Liu Y, et al. Community transmission of severe acute respiratory syndrome coronavirus 2 , Shenzhen, China. Emerg Infect Dis. 2020;26(6):1320-3.

5. Nicola M, Alsafi Z, Sohrabi C, Kerwan A, Al-Jabir A, losifidis C, et al. The socio-economic implications of the coronavirus pandemic (COVID-19): A review. Int J Surg. 2020;78:185-93.

6. Hennessy B, Vicari J, Bernstein B, Chapman F, Khaykis I, Littenberg G, et al. Guidance for resuming Gl endoscopy and practice operations after the COVID-19 pandemic. Gastrointest Endosc. 2020;92(3):743-7.e1.

7. Forde JJ, Goldberg D, Sussman D, Soriano F, Barkin JA, Amin S. Yield and implications of pre-procedural COVID-19 PCR testing on routine endoscopic practice. Gastroenterology. 2020 May 25;S0016-5085(20)34734-X. doi: 10.1053/j.gastro.2020.05.062. Online ahead of print.

8. Forbes N, Smith ZL, Spitzer RL, Keswani RN, Wani SB, Elmunzer BJ; North American Alliance for the Study of Digestive Manifestations of COVID-19. Changes in gastroenterology and endoscopy practices in response to the COVID-19 pandemic: Results from a North American survey. Gastroenterology. 2020;159(2):772-4.e13.

9. Repici A, Aragona G, Cengia G, Cantù P, Spadaccini M, Maselli R, et al; Italian GI-COVID19 Working Group. Low risk of covid-19 transmission in GI endoscopy. Gut. 2020 Apr 22:gutjnl-2020-321341. doi: 10.1136/gutjnl-2020-321341. Online ahead of print.

10. Gupta S, Shahidi N, Gilroy N, Rex DK, Burgess NG, Bourke MJ. A proposal for the return to routine endoscopy during the COVID-19 pandemic. Gastrointest Endosc. 2020;92(3):735-42.

11. Chu D, Pan Y, Cheng S, Hui KPY, Krishnan P, Liu Y, et al. Molecular diagnosis of a novel coronavirus (2019-nCoV) causing an outbreak of pneumonia. Clin Chem. 2020;66(4):549-55.

12. Holshue ML, DeBolt C, Lindquist S, Lofy KH, Wiesman J, Bruce H, et al. First case of 2019 novel coronavirus in the United States. N Engl J Med. 2020;382:929-36.

13. Corman VM, Landt O, Kaiser M, Molenkamp R, Meijer A, Chu DK, et al. Detection of 2019 novel coronavirus (2019-nCoV) by real-time RT-PCR. Euro Surveill. 2020;25(3):2000045.

14. Loeffelholz MJ, Tang YW. Laboratory diagnosis of emerging human coronavirus infections - the state of the art. Emerg Microbes Infect. 2020;9(1):747-56.

15. Guo L, Sun $X$, Wang $X$, Liang $C$, Jiang $H$, Gao $Q$, et al. SARS-CoV-2 detection with CRISPR diagnostics. Cell Discov. 2020;6:34.

16. Ben-Assa N, Naddaf R, Gefen T, et al. Direct on-the-spot detection of SARS-CoV-2 in patients. Exp Biol Med (Maywood). 2020;245(14):11871193. doi:10.1177/1535370220941819

17. Wang W, Xu Y, Gao R, Lu R, Han K, Wu G, et al. Detection of SARSCoV-2 in different types of clinical specimens. JAMA. 2020;323(18): 1843-4.

18. To K, Tsang O, Leung WS, Tam AR, Wu TC, Lung DC, et al. Temporal profiles of viral load in posterior oropharyngeal saliva samples and serum antibody responses during infection by SARS-CoV-2: an observational cohort study. Lancet Infect Dis. 2020;20(5):565-74. 
19. Wyllie AL, Fournier J, Casanovas-Massana A, Campbell M, Tokuyama M, Vijayakumar P, et al. Saliva is more sensitive for SARS-CoV-2 detection in COVID-19 patients than nasopharyngeal swabs. MedRxiv. Preimpresión de fecha: 22 de abril de 2020. doi: https://doi.org/10.1101/2020.04. 16.20067835

20. Becker D, Sandoval E, Amin A, De Hoff P, Diets A, Leonetti N, et al. Saliva is less sensitive than nasopharyngeal swabs for COVID-19 detection in community setting. MedRxiv. Preimpresión de fecha: 15 de mayo de 2020. doi: https://doi.org/10.1101/2020.05.11.20092338

21. Zhao J, Yuan Q, Wang H, Liu W, Liao X, Su Y, et al. Antibody responses to SARS-CoV-2 in patients of novel coronavirus disease 2019. Clin Infect Dis. 2020 Mar 28:ciaa344. doi: 10.1093/cid/ciaa344. Online ahead of print.

22. Guo L, Ren L, Yang S, Xiao M, Chang D, Yang F, et al. Profiling early humoral response to diagnose novel coronavirus disease (COVID-19). Clin Infect Dis. 2020;71(15):778-85.

23. Suhandynata RT, Hoffman MA, Kelner MJ, McLawhon RW, Reed SL, Fitzgerald RL. Longitudinal monitoring of SARS-CoV-2 IgM and IgG seropositivity to detect COVID-19. J Appl Lab Med. 2020 May 19:jfaa079. doi: 10.1093/jalm/jfaa079. Online ahead of print.

24. Li Z, Yi Y, Luo X, Xiong N, Liu Y, Li S, et al. Development and clinical application of a rapid IgM-IgG combined antibody test for SARS-CoV-2 infection diagnosis. J Med Virol. 2020 Feb 27:10.1002/jmv.25727. doi: 10.1002/jmv.25727. Online ahead of print.

25. Lassaunière $R$, Frische $A$, Harboe $Z B$, Nielsen $A C Y$, Fomsgaard $A$, et al. Evaluation of nine commercial SARS-CoV-2 immunoassays. MedRxiv. Preimpresión de fecha: 10 de abril de 2020. doi: https://doi.org/10.1101 /2020.04.09.20056325

26. Whitman JD, Hiatt J, Mowery CT, Shy BR, Yu R, Yamamoto TN, et al. Test performance evaluation of SARS-CoV-2 serological assays. MedRxiv. Preimpresión de fecha: 17 de mayo de 2020. doi: https://doi. org/10.1101/2020.04.25.20074856
27. Wölfel R, CormanVM, Guggemos W, Seilmaier M, Zange S, Müller MA, et al. Virological assessment of hospitalized patients with COVID-2019. Nature. 2020;581(7809):465-9.

28. Sethuraman $N$, Jeremiah SS, Ryo A. Interpreting diagnostic tests for SARS-CoV-2 [published online ahead of print, 2020 May 6. JAMA. 2020 May 6. doi: 10.1001/jama.2020.8259. Online ahead of print.

29. Lynch JB, Davitkov P, Anderson DJ, Bhimraj A, Cheng VC, Guzman-Cottrill J, et al. Infectious Diseases Society of America Guidelines on Infection Prevention for Health Care Personnel Caring for Patients with Suspected or Known COVID-19. Clin Infect Dis. 2020 Jul 27:ciaa1063. doi: $10.1093 / \mathrm{cid} / \mathrm{ciaa} 1063$. Online ahead of print.

30. Van Doremalen N, Bushmaker T, Morris DH, Holbrook MG, Gamble A, Williamson BN, et al. Aerosol and surface stability of SARS-CoV-2 as compared with SARS-CoV-1. N Engl J Med. 2020;382(16): 1564-7.

31. Chiu PWY, Ng SC, Inoue H, D Reddy N, Hu EL, Cho JY, et al. Practice of endoscopy during COVID-19 pandemic: position statements of the Asian Pacific Society for Digestive Endoscopy (APSDE-COVID statements). Gut. 2020;69(6):991-6.

32. Zheng S, Fan J, Yu F, Feng B, Lou B, Zou Q, et al. Viral load dynamics and disease severity in patients infected with SARS-CoV-2 in Zhejiang Province, China, January-March 2020: Retrospective cohort study. BMJ. 2020;369:m1443.

33. Hijnen D, Marzano AV, Eyerich K, GeurtsvanKessel C, Giménez-Arnau AM, Joly $\mathrm{P}$, et al. SARS-CoV-2 Transmission from presymptomatic meeting attendee, Germany. Emerg Infect Dis. 2020;26(8):1935-7.

34. Wei WE, Li Z, Chiew CJ, Yong SE, Toh MP, Lee VJ. Presymptomatic transmission of SARS-CoV-2 - Singapore, January 23-March 16, 2020. MMWR Morb Mortal Wkly Rep. 2020;69:411-5.

35. Dong Z, Tang A, Li K, Li P, Wang HL, Yi JP, et al. Potential presymptomatic transmission of SARS-CoV-2, Zhejiang Province, China, 2020 Emerg Infect Dis. 2020;26(5):1052-4. 